\title{
A reliability-based preventive maintenance methodology for the projection spot welding machine
}

\author{
Fayzimatov Ulugbek $^{\mathrm{a}}$, Sheng Buyun ${ }^{\mathrm{a}}$, Xiao Zheng ${ }^{\mathrm{a}}{ }^{*}$ and Toure Ismael ${ }^{\mathrm{a}}$
}

\begin{abstract}
${ }^{a}$ School of Mechanical and Electronics Engineering, Wuhan University of Technology, People's Republic of China CH R O N I C L E

\begin{tabular}{l}
\hline Article history: \\
Received: January 11, 2018 \\
Received in revised format: \\
March 3, 2018 \\
Accepted: May 9, 2018 \\
Available online: \\
May 10, 2018 \\
\hline Keywords: \\
Projection spot welding ma- \\
chine \\
Reliability \\
Maintainability \\
Preventive maintenance
\end{tabular}

An effective operations of a projection spot welding (PSW) machine is closely related to the effectiveness of the maintenance. Timely maintenance can prevent failures and improve reliability and maintainability of the machine. Therefore, establishing the maintenance frequency for the welding machine is one of the most important tasks for plant engineers. In this regard, reliability analysis of the welding machine can be used to establish preventive maintenance intervals (PMI) and to identify the critical parts of the system. In this reliability and maintainability study, analysis of the PSW machine was carried out. The failure and repair data for analysis were obtained from automobile manufacturing company located in Uzbekistan. The machine was divided into three main sub-systems: electrical, pneumatic and hydraulic. Different distributions functions for all subsystems was tested and their parameters tabulated. Based on estimated parameters of the analyzed distributions, PMI for the PSW machines sub-systems at different reliability levels was calculated. Finally, preventive measures for enhancing the reliability of the PSW machine sub-systems are suggested.
\end{abstract}

(C) 2018 by the authors; licensee Growing Science, Canada

\section{Introduction}

For several decades, the PSW machine has been extensively used in the automobile industry for assembling the bodies of modern cars. Projection welding is a welding process, in which metallic parts are joined at one or several points at once. This process is used in the automotive industry to fasten brackets, nuts and bolts to the metallic sheet. The modern car body contains up to 100 elements fastened by this method. Projection welding like any spot welding process has a major problem, which is high variation in quality of welding joints ( $\mathrm{Li}$ et al., 2001). For the most cases, the quality of the welding joints depends on the effective operation of the welding machine and its components (Kimchi \& Phillips, 2017). In this regard ensuring reliable and effective operation of the machine is essential in order to meet the established welding quality requirements. The problem of maintaining effective operations of the equipment in the automobile industry can be successfully solved by analyzing the reliability and maintainability of its operations (Smith \& Mobley, 2011). There are a number of techniques that have been successfully used to analyze the reliability and the maintainability of the system. For example, Rahimdel (2013) performed reliability and maintainability analysis of the pneumatic system of the rotary machine. This research

* Corresponding author.

E-mail address: reallylaugh@whut.edu.cn (X. Zheng) 
confirms the importance of reliability analysis to ensure safe and reliable operation of the system. Adhikary et al. (2012) carried out reliability and maintainability analysis of coal-fired thermal power plants for enhancing reliability and availability of the system. Ahmad (2018) presented an application of reliability based decision-making process for maintenance policy. Seyed et al. (2011) presented reliability-based preventive maintenance analysis for an electrical sub-system of the drum shearer. On the basis of the analysis, preventive maintenance programme for improving reliability and maintainability was established. Tsarouhas and Fourlas (2015) carried out reliability and maintainability analysis of an automated robotic system. The presented analysis identified critical elements of the robotic system and determined PMI. One of the main objectives of these techniques is to increase the reliability and the maintainability of the system through timely preventive maintenance activities. Preventive maintenance is a type of maintenance that is directed to prevent or predict failure before complete breakdown of the system (Aggarwal et al., 2017). The process of predicting (forecasting) preventive maintenance activities determines the technical conditions of the system and its components by monitoring equipment failures and repair modes for a certain period.

In this research, the reliability and the maintainability analysis based on statistical modeling techniques is used to determine PMI for the PSW machine. To analyze the reliability and maintainability of welding machine, data on failures and repairs were collected from an automobile assembling company located in Uzbekistan. The time before failure (TBF), time to repair (TTR), failure frequency and failure causing of all sub-systems of the PSW machine were obtained and classified. The critical sub-system that significantly affects the reliability of the machine is also identified. The best-fit distribution parameters for failure and repair data were determined. Based on the fitted distribution and corresponding parameters, intervals for a preventive maintenance are developed. Finally, preventive measures for enhancing the reliability of the PSW machines sub-systems are suggested. The proposed method can be helpful for plant engineering and maintenance staff to determine critical parts of the machine, to organize effective maintenance strategy for the projection-welding machine and any other types of welding machines.

\section{Projection spot welding machines structure}

The structure of the PSW machine may vary widely depending on the design and welding operations in which machine performs. However, regardless of these characteristics, any spot welding machine mainly consists of the following sub-systems: Electrical system, Pneumatic System (for machines with pneumatic actuators ) and Water, cooling system (will be called hydraulic system). The electrical sub-system of the machine is designed to provide heat in the weld zone.

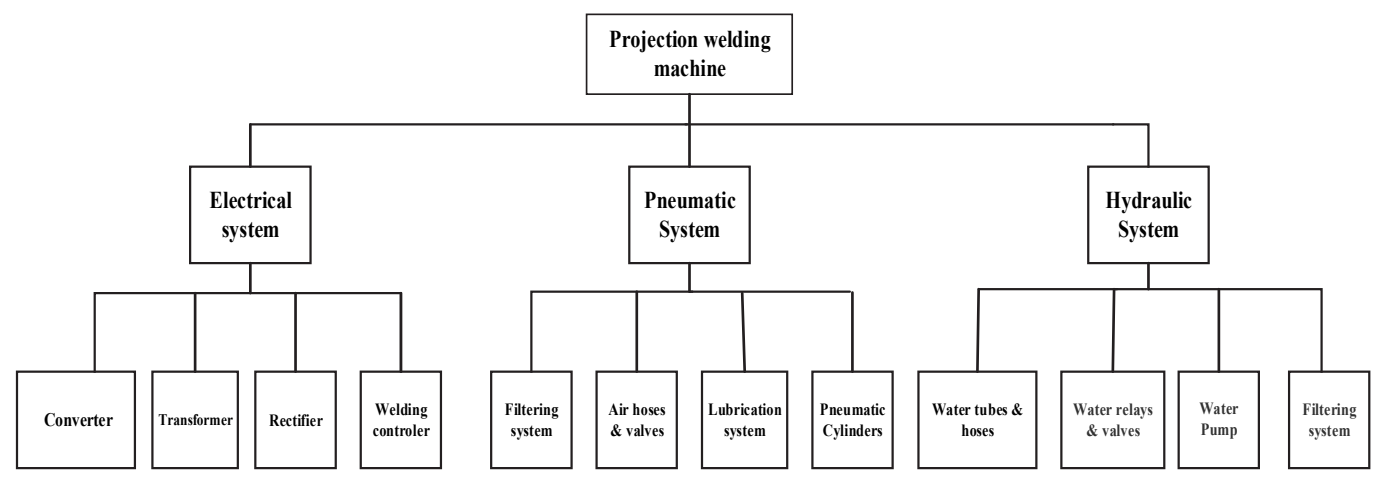

Fig. 1. The hierarchical structure of the PSW machine under study

It mainly consists of 4 elements, i.e. converter, single phase transformer, welding controller and rectifier unit with capacitor banks. The electrodes and electrode holders are also part of the electrical system of 
the machine, but they are replaceable parts and have a much shorter useful life cycle, therefore, they will not be considered in this research. The pneumatic sub-system is designed to supply compression force, which allows electrodes to move to a given position during the welding of parts. The pneumatic subsystem consists of air filtering system, pneumatic connections (air hoses and tubes), and lubrication system and pressure cylinders. The hydraulic sub-system is designed to remove heat from current-carrying parts of the machine. It consists of water connections (water tubes and hoses), water relays $\&$ valves, a water pump and a water filtering system. Main components of described sub-systems are connected in series, which means that the failure of any element of the sub-system highly affects the reliability of the overall system and consequently weld quality. Fig. 1 illustrates the hierarchical decomposing of the PSW machine into the main sub-systems and sub-systems components.

\section{The failure rate of the projection spot welding machine}

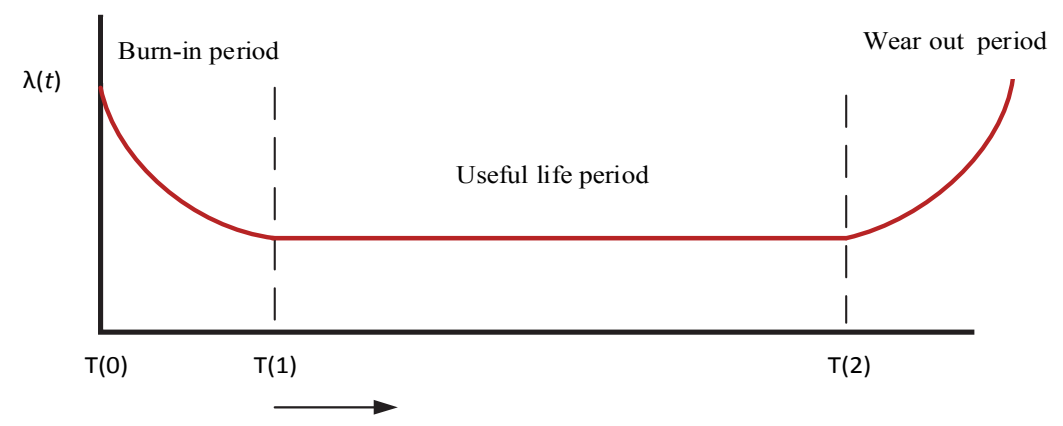

Fig. 2. Bathtub failure rate curve

The failure rate $\lambda$ or the hazard rate is the frequency of the component failure at the time $t$. It is expressed as a number of failures per unit hour (Aggarwal et al., 2017). For most components of the PSW machine, the dependence of the failure rate $\lambda$ at the time $t$ has the form of a U-shaped curve, in the reliability engineering called "bathtub curve" Fig. 2. This curve consists of 3 parts:

- Burn-in period $\left(T_{o}-T_{1}\right)$ or "infant mortality" with a decreasing failure rate, where failures appear mainly due to manufacturing and installation defects.

- Useful life period $\left(T_{1}-T_{2}\right)$ or "normal life", where failure rate is a constant and has random, instantaneous hazard form, primarily due to the inappropriate equipment exploitation, accidental load changes and unfavorable external factors. This period begins immediately after Burn-in period and ends before Wear out period.

- Wear out period, where the system or element has exhausted its resource so that the failure rate in this period begins to increase.

\section{Reliability}

Reliability is the characteristic of a system expressed by the probability that a system/component can perform a required function for which it was designed, in given conditions for a given period of time (Waghmode \& Patil, 2016). Mathematical definition of reliability is presented by

$$
R(t)=1-\int_{0}^{t} f(t) d t
$$


where $R(t)$ is the reliability function at time $t$ and $f(t)$ failure probability density function. For exponential distribution reliability of the system is defined as

$$
R(t)=e^{-\lambda(t-\gamma)},
$$

where $\lambda$ is a failure rate and $\gamma$ location parameter. The exponential distribution applied when failure rate is constant and often used to analyses reliability of the system or component during normal life period, also known as "useful life" in "Bathtub curve" Fig. 2. For Weibull distribution reliability of the system is defined as (Garg, 2014).

$$
R(t)=\exp \left[-\left(\frac{t}{\theta}\right)^{\beta}\right]
$$

where $\beta$ is a shape parameter and $\theta$ is the scale parameter. The Weibull distribution is flexible and its shape parameter $\beta$ has properties to describe any conditions of failure (Puertollano et al., 2015). A parameter $\beta<1$ signifies a decreasing failure rate, and $\beta>1$ signifies an increasing failure rate. When parameter $\beta=1$ the failure rate is constant and Weibull distribution is coincide with exponential distribution (Tsarouhas \& Fourlas, 2015). For Gamma distribution reliability of the system defined as

$$
R(t)=\frac{\lambda^{\beta} t^{(\beta-1)}}{\Gamma(\beta)} \exp (-\lambda t)
$$

where $\lambda$ failure rate of the system/component, $\beta$ shape parameter. The gamma distribution best describes the distribution of the independent random variables. For log-normal distribution reliability of the system is defined as

$$
R(t)=\frac{1}{\sqrt{2 \pi \sigma}} \int_{0}^{t} \frac{1}{t} \exp \left(\frac{(\operatorname{Ln}(t)-\mu)^{2}}{2 \sigma^{2}}\right) d t
$$

where $\sigma$ is a standard deviation and $\mu$ is a mean. Lognormal distribution is often used to describe the failure of the system caused by fatigue of the elements.

\section{Maintainability}

Maintainability is the characteristic of the system expressed by the probability that maintenance of the system/component will be performed within a given period of time (Barringer, 1997). Qualitatively maintainability is defined as the ability of the system/component to be restored to an operational state. Quantitatively it has probabilities and is measured based on the total downtime for maintenance as

$$
M(t)=\int_{0}^{t} f(t) d t
$$

where $M(t)$ is the maintainability function at time $t$ and $f(t)$ repair probability density function.

\section{Failure data collection}

The main source of information for calculating reliability and maintainability indices is the statistical data on the failures and repairs of all elements of the machine. In this study for analyzing the reliability and the maintainability of the PSW machine, data of a period of 12 months was collected from the automobile assembly plant, located in Uzbekistan. The company is specialized in manufacturing of welding and stamp details for the body of the car. The plant is equipped with modern press and welding equipment and has a strict quality control system based on standards ISO 16949 and QSB (quality systems basics). Under the requirements of these standards, the company pays special attention to maintaining maintenance documentation. The failure data for statistical analysis were obtained from the analysis of operational information of the machine, that was recorded in the maintenance activity sheet illustrated in Table 1. The maintenance staff is responsible for keeping records of failures. The records depict the exact date of the failure, time to repair, type of failed component and written notice from the operator for waiting time for maintenance team. Finally, the TBF and TTR of the electric, pneumatic and 
hydraulic sub-systems were calculated and classified. The TBF of the system was defined as the time elapses, from the moment the equipment start operating after a failure until the moment it goes down again and stops operation due to the new failure. TTR is defined as the time that elapses from the moment the equipment stops functioning until the moment it starts operating again (Khoshalan et al., 2015). One of the main problem in data collection was classifying and calculating values of TBF and TTR from the maintenance sheet. Some type of equipment's stoppage for maintenance where caused by the fault of the operator. In an attempt to improve weldability of the items, operators changed the machines welding setup. This unauthorized interference in the operation of the machine can affect the weld quality outcomes, which can be identified only by quality control inspection or after testing the weld items. In this case, the machine is stopped for reconfiguration of welding parameters and full inspection. This type of machine stoppage is classified as "human-related" failures and calculated for failure frequency analysis in the next section but not included in reliability analysis of the PSW machine in this research.

Table 1

The format of data recording sheet

\begin{tabular}{|c|c|c|c|c|c|c|}
\hline $\begin{array}{l}\text { Machine } \\
\text { number }\end{array}$ & & & Components & Failure Type & $\begin{array}{l}\text { Type of the } \\
\text { maintenance } \\
\text { performed }\end{array}$ & $\begin{array}{l}\text { Waiting time for } \\
\text { the repair service }\end{array}$ \\
\hline \multirow[b]{2}{*}{14} & Start time & End time & & \multirow[b]{2}{*}{ Damage } & & \\
\hline & $9: 35$ & $9: 45$ & Hose connection & & Replacement & $5 \mathrm{~min}$ \\
\hline
\end{tabular}

\section{Failure data analysis}

An analysis of data on failures and repairs of the PSW machines sub-systems consists of several steps. The first step is an analysis of failures frequency of the PSW machines sub-systems and their elements. Failure frequency analysis allows to identify critical sub-system of the machine and understand the impact of critical sub-systems on machine reliability. The failure frequency of the PSW machines subsystems was analyzed by using Pareto chart. The result of the analysis is shown in Fig. 2. According to the figure, the hydraulic sub-system has the most frequent failure occurrences of $39 \%$. The second frequent failure in the pneumatic sub-system is $35 \%$. The electric sub-system has $20 \%$ of all failures. The last frequent failure occurrence caused by the fault of the operators is $6 \%$ of all the failures.

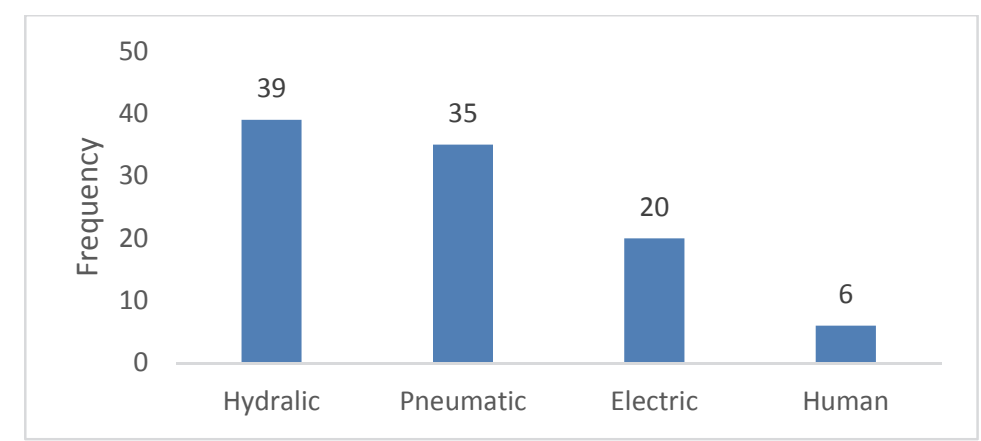

Fig. 2 Pareto analysis of Projection Spot Welding Machine

\subsection{Trend and serial correlation}

The reliability and the maintainability analysis are usually based on the assumption that TBF and TTR data are independent and identically distributed (iid) in the time domain (Adhikary et al., 2012). The failure and repair data iid means that there are no trends in the data sample and no relationship among the failure mechanism. Therefore, next step of data analysis is to test the hypothesis that the data under analysis is $\mathrm{iid}$. Thus, the null-hypothesis $H_{0}$ : No-trend in data and the alternative hypothesis $H_{1}$ : trend in data is considered. If the hypothesis of iid for the TBF and TTR is true, then data should be modeled using renewal process (RP). RP method is used to model repairable systems, which means repair will restore the system to "as good as new" condition. If the assumption that the data iid is not true, then 
nonhomogeneous Poisson process (NHPP) should be applied to model the data. NHPP method is applied to analyze non-repairable systems with the "as bad as old" restoration (GölbAşı \& Demirel, 2017). The data iid assumption can be verified by using trend test and serial correlation test (Hadi H. 2012). Trend test can be done analytically and graphically. Analytical method can be performed using the method suggested in the military hand book-189 (Amsc \& Sess, 2011)

$$
U=2 \sum_{i=1}^{n-1} \ln \frac{T_{n}}{T_{i}},
$$

where $n$ is total number of failures, $T_{n}$ is time of the $n$th failure and $T_{i}$ time of the $i$-th failure. Under the null hypothesis that data has no trends, the test statistic $U$ is Chi squared distributed with a 2(n - 1) degree of freedom. If calculated test statistic $U$ located between lower confidence level $x_{0.5}^{2}$ and upper confidence level $x_{0.95}^{2}$ that indicates the data has no trends (Khoshalan et al., 2015) A test for serial correlation can be performed graphically by plotting the $i^{\text {th }}$ TBF against the $\left(i-1^{t h}\right)$ TBF for $i=1,2 \ldots n$, where $n$ is a total number of failures. If TBF and TTR data are independent, then the points should be scattered randomly on the diagram without indication any pattern (Aggarwal et al., 2017). The validation of the trend for TBF and TTR data has been examined and the results are presented in Table 2. The results show that there is no trend in TBF and TTR data. The results of the test for serial correlation for the PSW machine sub-systems TBF and TTR data are given in Fig 4. It is observed that data points are randomly scattered, which indicates that there is no significant correlation in TBF and TTR data for all sub-systems of the machine. Based on the results of the tests, the assumption that the data iid is valid for all subsystems, thus the null-hypothesis is accepted and RP model is used for the reliability and the maintainability analysis.

\section{Table 2}

The computed value of the test statistic U for TBF and TTR data

\begin{tabular}{|c|c|c|c|c|c|c|}
\hline Subsystem & Variable & $\begin{array}{l}\text { Number of } \\
\text { failures }\end{array}$ & $\begin{array}{l}\text { Degree of } \\
\text { freedom }\end{array}$ & $\begin{array}{l}\text { Calculated } \\
\text { statistics U }\end{array}$ & $\begin{array}{c}\text { Lower } \\
\text { confidence level }\end{array}$ & $\begin{array}{c}\text { Upper } \\
\text { confidence level }\end{array}$ \\
\hline \multirow[t]{2}{*}{ Electrical } & TBF & 63 & 124 & 142 & 99 & 170 \\
\hline & TTR & & 124 & 109 & 99 & 170 \\
\hline \multirow[t]{2}{*}{ Pneumatic } & TBF & 109 & 216 & 223 & 182 & 251 \\
\hline & TTR & & 216 & 204 & 182 & 251 \\
\hline \multirow[t]{2}{*}{ Hydraulic } & TBF & 123 & 244 & 235 & 208 & 281 \\
\hline & TTR & & 244 & 272 & 208 & 281 \\
\hline
\end{tabular}

The next step of the analysis is identification of the best-fit distribution for TBF and TTR data set of the electrical, pneumatic and hydraulic sub-systems. The identification of the correct distribution that accurately fits failures and repairs data is very important in reliability and maintainability analysis. If the sample data is analyzed with wrong distribution function, this can lead to substantially different results. Many computer reliability software contains tools for analyzing best-fitted distribution. Based on the estimated parameters of the analyzed, the distributions of the reliability and the maintainability of the PSW machine can be calculated. The results of the analysis can be represented graphically plotting the estimated parameters of failures/repairs $(\lambda / \mu)$ over operational time $t$. This graph is a simple visual representation of change in the failure flow, allowing based on the curved shape to determine the lifetime of an element and failure characteristics of the system. This also can be done with the help of reliability software. In this research to analyze the best-fitted distribution, Easy Fit 5.4 reliability software has been used. The Kolmogorov-Smirnov (K-S) nonparametric test has been applied to estimate the statistical values and parameters of the fitted distributions. In Table 3, different distribution functions (Gamma, Log-normal, Exponential, Weibull) for all sub-systems have been tested. Statistical results of failures indicate that in the operational time the elements of the PSW machines electrical and pneumatic subsystems follow a Weibull distribution with shape parameter $\beta>1$, which is correspondent to "wear out" period in "Bathtub Curve" Fig. 2. The failure behavior of hydraulic sub-systems elements follows the exponential distribution with failure rate $\lambda=0.0612$, which correspondent to "useful life" $\left(T_{1}-T_{2}\right)$ period in "Bathtub Curve". 


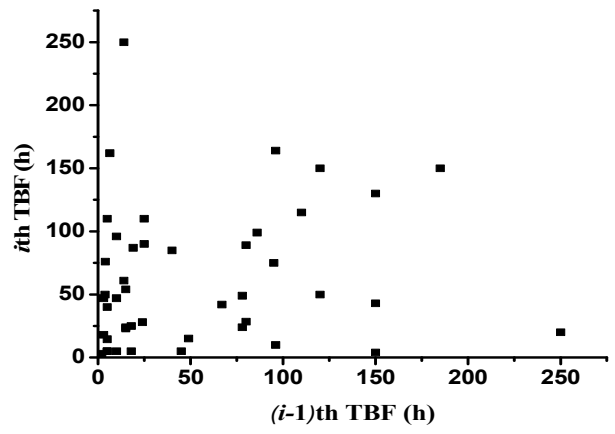

(a)

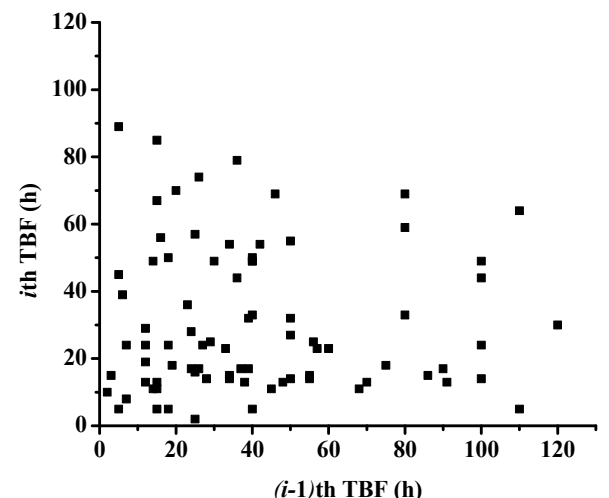

(c)

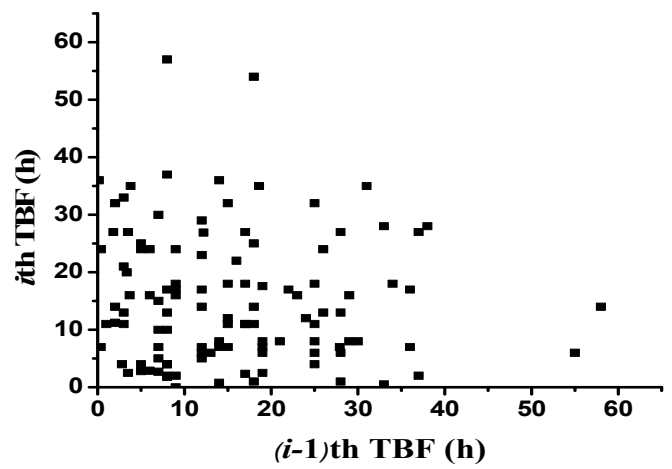

(e)

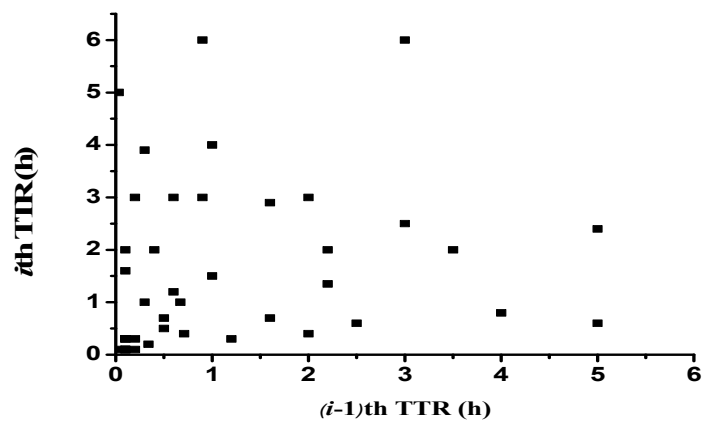

(b)

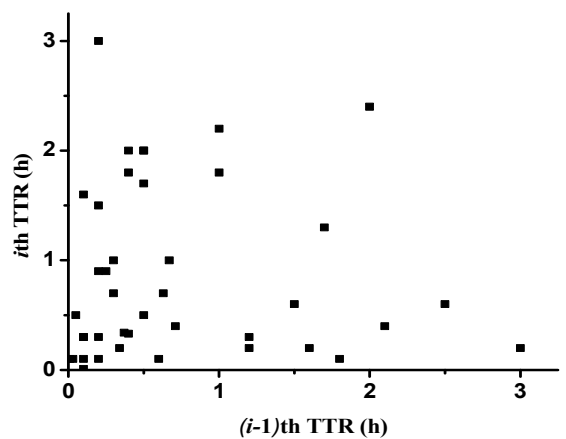

(d)

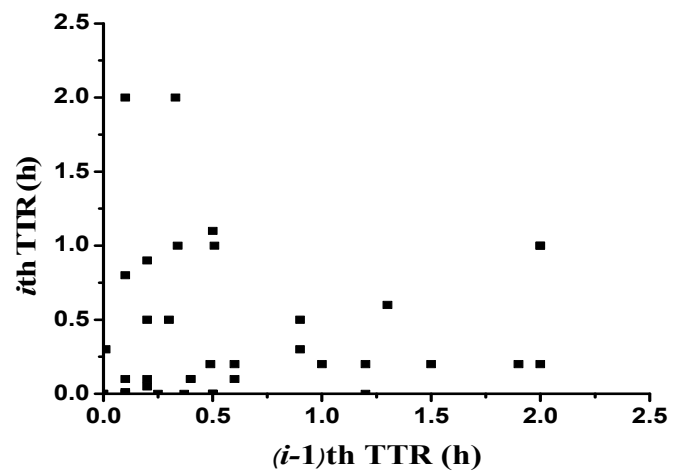

(f)

Table 3

Fig. 4. Results of serial correlation test for TBF and TTR data

The results of best-fit distributions for TBF data set

\begin{tabular}{lcccccc}
\hline Sub-system & Gamma & Log-normal & Exponential & Weibull & Best-fit & Parameters \\
\hline Electrical & 0.0816 & 0.0924 & 0.2200 & 0.0754 & Weibull & $\alpha=1.72 \beta=83.58$ \\
Pneumatic & 0.1177 & 0.0963 & 0.1084 & 0.0861 & Weibull & $\alpha=1.044 \beta=22.58$ \\
Hydraulic & 0.1041 & 0.0859 & 0.0784 & 0.1065 & Exponential & $\lambda=0.061$ \\
\hline
\end{tabular}

Table 4

The results of best-fit distributions for TTR data set

\begin{tabular}{lcccccc}
\hline Sub-system & Gamma & Log-normal & Exponential & Weibull & Best-fit & Parameters \\
\hline Electrical & 0.13729 & 0.1302 & 0.1628 & 0.1019 & Weibull & $\alpha=1.44 \beta=3.16$ \\
Pneumatic & 0.10396 & 0.1605 & 0.1534 & 0.1050 & Gamma & $\alpha=1.38 \beta=0.88$ \\
Hydraulic & 0.1331 & 0.1482 & 0.1821 & 0.1889 & Gamma & $\alpha=1.53 \beta=0.43$ \\
\hline
\end{tabular}


In Table 4 the best-fit distributions of TTR data for all subsystems is shown. According to the table pneumatic and hydraulic sub-systems follow Gamma distribution with parameters $\alpha=1.3825, \beta=0.8882$ and $\alpha=1.5376, \beta=0.4334$, respectively.

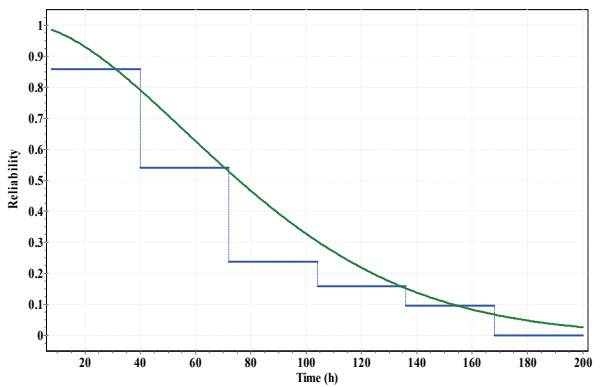

(a)

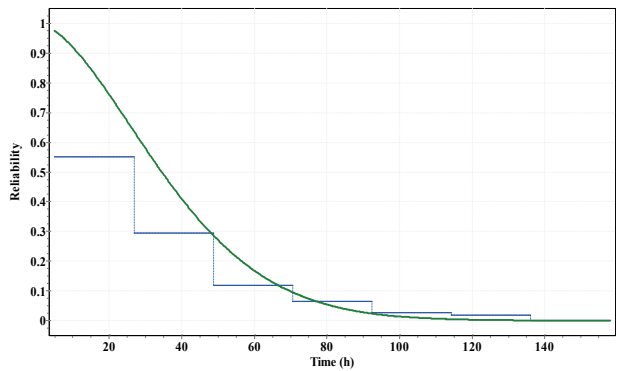

(c)

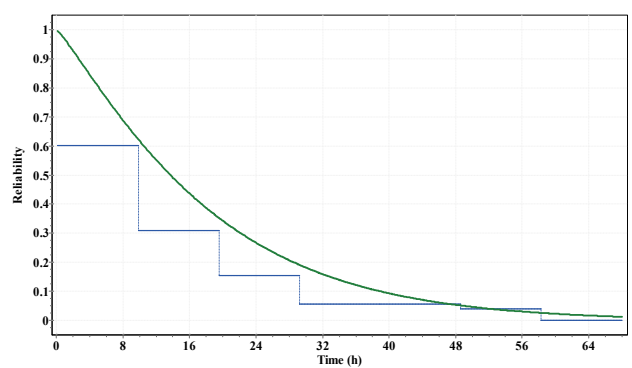

(e)

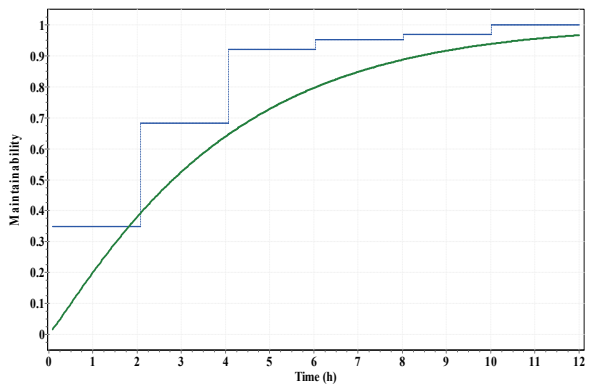

(b)

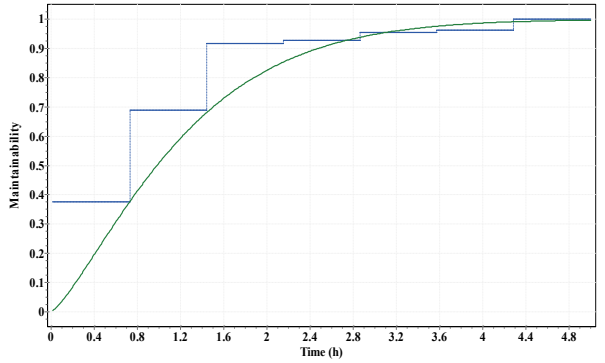

(d)

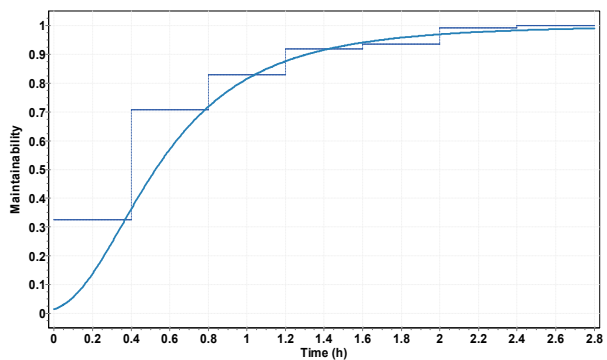

(f)

Fig. 5 Reliability and maintainability plots of the PSW machines sub-systems.

Electrical sub-system follows Weibull distribution with parameters $\alpha=1.4499$ and $\beta=3.1683$. The $\mathrm{R}(\mathrm{t})$ and $\mathrm{M}(\mathrm{t})$ of welding machines sub-systems were calculated using the best-fit distribution parameters and Eqs. (2-4) for Exponential, Weibull and Gamma distributions. The graphical representation of the analysis is illustrated in Fig. 5. From the Fig. 5(a) it is observed that the probability of the electric subsystem failure-free operation in 20 hours is $91 \%$, which indicates that electric sub-system has the highest reliability level among other sub-systems. However, maintainability plot Fig. 5(b) for electric sub-system shows that there is only $35 \%$ probability that failure in the system will be repaired in 2 hours. It is also observed in Fig. 5(c) that the probability of the pneumatic sub-system reached $75 \%$ after 20 hours' operation, without performing maintenance action after 60 hours' reliability will reach $30 \%$. The maintainability plot Fig. 5(d) of pneumatic sub-system shows that there is a $90 \%$ chance that any failure in the system will be repaired within 2 hours of the maintenance operation. The lowest reliable sub-system of the PSW according to Fig. 5(e) is hydraulic sub-system. The reliability of hydraulic sub-system reached $35 \%$ within 20 hours of operation and maintainability $95 \%$ within 2 hours of the maintenance operation. 


\section{Maintenance scheduling}

In order to maintain the high-reliability level of the machine during the operational phase, it is necessary to carry out periodic preventive maintenance (Tomasevicz, 2006). Over the course of the analysis, it was determined that the company is carrying out scheduled repairs with a periodicity set by the manufacturer of the equipment, which does not take into consideration all the factors that are encountered during the exploitation of the equipment. The highest efficiency of the maintenance can be achieved in the case when the frequency of the maintenance is consistent with the technical condition of the equipment and operating modes (Kobbacy \& Murthy, 2008). As can be seen from the above analysis, the reliability and maintainability analysis is a very good tool to predict the failure of the system or component. The same approach can be used to schedule PMI. By using reliability plots Fig. 5, PMI of the PSW machines subsystems for the different reliability levels are calculated and presented in Table 5. In order to estimate the PMI, the criticality of the PSW machines failures in the automobile industry is taken into account and $90 \%$ level of the reliability is suggested. From Table 5, to achieve $90 \%$ reliability for an electric subsystem of welding machines, the preventive inspection must be performed after every 40 hours' operations. For pneumatic sub-system, $90 \%$ reliability can be achieved if inspections are carried out after $17 \mathrm{~h}$ or almost after 3 shift operations. The interval for the hydraulic system is $8 \mathrm{~h}$ or after 1 shift operation.

Table 5

Reliability-based PMI for PWM sub-systems.

\begin{tabular}{llll}
\hline Level of reliability (\%) & 90 & 80 & 70 \\
\hline Electric sub-system (h) & 40 & 50 & 65 \\
Pneumatic sub-system (h) & 17 & 22 & 26 \\
Hydraulic sub-system (h) & 8 & 14 & 18 \\
\hline
\end{tabular}

\section{Discussion and Conclusion}

This paper has presented the reliability and the maintainability analysis using a statistical modeling technique to analyze the reliability characteristics of a projection welding machines electrical, pneumatic and hydraulic sub-systems. This approach was then used to schedule PMI. The reliability analysis has shown that the hydraulic system was the most critical sub-system of the machine. The probability of the system failure-free operation in 20 hours was $35 \%$. The failure behavior of the hydraulic sub-system followed an exponential distribution which is correspondent to the "useful life" period, where failures had random and instantaneous hazard form. The failures like hose rupture, water pump seals, clogging of filters, pipes, and tubes with dirt and scum. These failures led to a reduction of distribution cooling water to the current carrying parts of the machine. Current carrying parts of the machine needed an adequate flow of water with a minimum water flow $7-10 \mathrm{~L} / \mathrm{min}$ and pressure $\mathrm{kPa} 250$. For the hydraulic system, PMI should include: daily monitoring of cooling rate and pressure level of the water, checking hydraulic connections and systematical replacement the water filter. The hydraulic system is an important factor that ensures the reliable and effective operation of the PSW machine, therefore preventive maintenance inspection should pay special attention to this sub-system. The most reliable sub-system of the machine based on reliability analysis was an electrical system. The probability of sub-system failure-free operation in 20 hours was $91 \%$. The main causes of failures for the electrical part of the machine was oxidation of electrical connection and over-voltage, which may result in a systems overheating. Maintainability analysis of the electrical system has shown that there was only $35 \%$ probability that failure in the system could be repaired in 2 hours. Low maintainability level of the system can be explained by the fact that the failure of an electrical part like welding transformers, requires considerable time for repair. For the electric system, PMI should include: disassembling secondary electrical connections for cleaning and buffing, checking the operation of the control unit, cleaning electrical parts from dust, dirt, and slags. The analysis of failure frequency has shown that $25 \%$ of all failures are from pneumatic sub-system. The main causes of failures in pneumatic sub-system are leakage of compressed air (due to damage of pipes and hoses) and the clogging of filters, pipes and hoses. Preventive maintenance should include: monitoring the oil level in lubrication system, timely replacing air and oil filters, checking air connections, checking cylinders and piston rods. Maintenance authorities and plant managers can analyze the reliability 
parameters of welding machine and define maintenance policy for welding machines by using above presented approach.

\section{Acknowledgement}

This work was supported by the Science and Technology Support Program of Hubei Province, China (Grant No.2015BAA058) and the Fundamental Research Funds for the Central Universities (WUT: 2017IVA019).

\section{References}

Adhikary, D., Bose, D., Chattopadhyay, S., Bose, G., \& Mitra, S. (2012). RAM investigation of coal-fired thermal power plants: a case study. International Journal of Industrial Engineering Computations, 3(3), 423-434.

Aggarwal, A., K., Kumar, S., \& Singh, V. (2017). Mathematical modeling and reliability analysis of the serial processes in feeding system of a sugar plant. International Journal of System Assurance Engineering and Management, 8(1), 435-450.

Ahmad, R. (2018). Reliability analysis comparison on punching tool sets due to different maintenance decisions: a case study from the pulp manufacturing industry. The International Journal of Advanced Manufacturing Technology, 94(5-8), 1969-1979.

Amsc, N., \& Sess, A. A. (2011). Department of Defense Handbook Reliability Growth Management. Menachem.

Barringer, H. P. (1997). Availability, reliability, maintainability, and capability. Triplex Chapter of the Vibrations Institute. Humble, TX: Barringer and Associated Inc.

Khoshalan, H. A., Torabi, S. R., \& Maleki, D. (2015). RAM analysis of hydraulic system of earth pressure balance tunnel boring machine. Indian Journal of Science and Technology, 8(28).

Kobbacy, K. A. H., \& Murthy, D. P. (Eds.). (2008). Complex system maintenance handbook. Springer Science \& Business Media.

Kimchi, M., \& Phillips, D. H. (2017). Resistance Spot Welding: Fundamentals and Applications for the Automotive Industry. Synthesis Lectures on Mechanical Engineering, 1(2), i-115.

Li, W., Cheng, S., Hu, S. J., \& Shriver, J. (2001). Statistical investigation on resistance spot welding quality using a two-state, sliding-level experiment. Journal of manufacturing science and engineering, 123(3), 513-520.

GölbAş1, O., \& Demirel, N. (2017). Risk-based reliability allocation methodology to set a maintenance priority among system components: A case study in Mining. Eksploatacja i niezawodnosc, 19(2), 191.

Garg, H. (2014). Reliability, availability and maintainability analysis of industrial systems using PSO and fuzzy methodology. Mapan, 29(2), 115-129.

Hadi Hoseinie, S., Ataei, M., Khalokakaie, R., Ghodrati, B., \& Kumar, U. (2012). Reliability analysis of drum shearer machine at mechanized longwall mines. Journal of quality in maintenance engineering, 18(1), 98-119.

Puertollano, I. D. J., Macapuno, M. J. V., \& Chien, Y. C. (2015). Determination of Burn-in Period Based on Reliability Target for Product Failure Time with Weibull Distribution. Proceedings of the 2015 International Conference on Industrial Engineering and Operations Management Dubai, UAE.

Rahimdel, M. J., Ataei, M., Khalokakaei, R., \& Hoseinie, S. H. (2013). Reliability-based maintenance scheduling of hydraulic system of rotary drilling machines. International Journal of Mining Science and Technology, 23(5), 771-775.

Seyed, H. H., Mohammad, A., Reza, K., \& Uday, K. (2011). Reliability and maintainability analysis of electrical system of drum shearers. Journal of Coal Science and Engineering (China), 17(2), 192-197.

Smith, R., \& Mobley, R. K. (2011). Rules of thumb for maintenance and reliability engineers. Butterworth-Heinemann.

Tomasevicz, C. L., \& Asgarpoor, S. (2006, September). Preventive maintenance using continuous-time semi-Markov processes. In Power Symposium, 2006. NAPS 2006. 38th North American (pp. 3-8). IEEE.

Tsarouhas, P. H., \& Fourlas, G. (2015). Reliability and maintainability analysis of a robotic system for industrial applications: a case study. International Journal of Perform Engineering, 11(5), 453-462.

Waghmode, L. Y., \& Patil, R. B. (2016). Reliability analysis and life cycle cost optimization: a case study from Indian industry. International Journal of Quality \& Reliability Management, 33(3), 414-429.

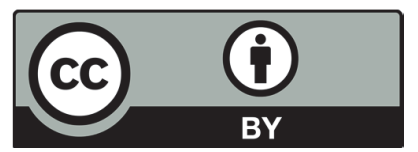

(C) 2018 by the authors; licensee Growing Science, Canada. This is an open access article distributed under the terms and conditions of the Creative Commons Attribution (CCBY) license (http://creativecommons.org/licenses/by/4.0/). 